\title{
HANNAH ARENDT LECTORA DE FRANZ KAFKA: UNA MIRADA PEDAGÓGICA A LA RAZÓN POÉTICA
}

\author{
Hannah Arendt reader of Franz Kafka: \\ a pedagogical approach to the poetic reason
}

\author{
Hannah Arendt lectrice de Franz Kafka: \\ un regard pédagogique sur la raison poétique
}

\author{
Serena BILLITTERI \\ Università degli Studi di Cassino e del Lazio Meridionale. Dipartimento di Scienze \\ Umane, Sociali e della Salute. Via S. Angelo - località Folcara 03043 Cassino, Italia. \\ serenabillitteri@gmail.com
}

Fecha de recepción: enero de 2018

Fecha de aceptación: marzo de 2018

\section{RESUMEN}

Abordar el tema de la razón poética en Hannah Arendt, a través de una intención pedagógica, ha abierto principalmente dos caminos de investigación. Las primeras consideraciones nos han guiado hasta el reconocimiento del pensamiento poético, con su proximidad con el lenguaje común, como la forma humana de comprender de una manera diferente y esencial, forma de reflexionar sobre lo que es imprevisible e indefinible. Un segundo camino consiste en mostrar cómo la razón poética se puede desarrollar, en educación, a partir de una revaluación de la tradición y del pasado. Casi que Hannah Arendt quiera indicar el patrimonio humanístico, a menudo desacreditado por las ciencias de la formación, como el lugar desde donde mirar el mundo como algo en común, un hogar compartido, desde el que puede empezar una forma auténtica de comunicación.

Palabras clave: pensamiento poético; pedagogía de la presencia; memoria y tradición; Franz Kafka. 


\section{SUMMARY}

By addressing the issue regarding the poetic reason in Hannah Arendt from a pedagogical perspective, two paths of investigation can be defined. The first considerations guided us to the recognition of the poetic thinking, along with its similarity to the common language, as the human manner of understanding in a different and essential way, and of reflecting on what is unpredictable and indefinable. A second approach is to show how poetic reason can be developed, in education, through a revaluation of the tradition and the past. It seems that Hannah Arendt wants to indicate the humanistic heritage, often discredited by behavioral sciences, as the place from where the world can be seen as something in common, as a shared house, where an authentic type of communication can begin. Kafka.

Key words: poetic thinking; pedagogy of presence; memory and tradition; Franz

SOMMAIRE

En abordant la question de la raison poétique dans Hannah Arendt d'un point de vue pédagogique, deux chemins d'investigation peuvent être définies. Les premières considérations nous ont guidés vers la reconnaissance de la pensée poétique, avec sa ressemblance avec le langage commun, comme la manière humaine de comprendre d'une manière différente et essentielle et de réfléchir sur ce qui est imprévisible et indéfinissable. Une deuxième approche consiste à montrer comment la raison poétique peut être développée, dans l'éducation, à partir d'une réévaluation de la tradition et du passé. Il semble qu'Hannah Arendt veut indiquer le patrimoine humaniste, souvent discrédité par les sciences du comportement, comme le lieu d'où le monde peut être vu comme quelque chose en commun, comme une maison partagée, à partir de laquelle une forme authentique de communication peut commencer.

Mots clés: pensée poétique; pédagogie de la présence; mémoire et tradition; Franz Kafka.

\section{INTRODUCCIÓN}

La primera lucha a la que se asiste con el nacimiento de la filosofía, llevada a cabo en el tiempo diacrónico de la conversación de un maestro y de un discípulo, Sócrates y Platón, es entre la opinión (doxa), que se propaga convenciendo a los demás, y la tiranía de la verdad absoluta. Es la violencia de este tipo de verdad la que destrona a Peithō, la diosa de la seducción y de la persuasión, de su posición legítima al residir entre los dioses protectores de Atenas.

La oposición aquí es entre una comunicación personal, reflejo de los códigos interpretativos y existenciales de cada hombre, y una comunicación científica, asertiva, que nunca cede el paso al subjetivismo. 
Hannah Arendt nos muestra -en las clases impartidas sobre Sócrates en la Notre Dame University (EE. UU.) en 1954- cómo la doxa, que ha salido perdiendo de la lucha contra la verdad absoluta, epistème, y que al día de hoy conserva los rasgos resbaladizos de lo no necesario y de lo superfluo, no solo constituye una manera personal de ver el mundo, sino, encontrándose con las opiniones de los otros, crea un precipitado único: que «a pesar de todas las diferencias entre los hombres y sus posiciones en el mundo [...] tanto tú como yo somos humanos» (Arendt, 2008, 52).

En la doxa -que según la etimología que nos da Parménides, derivaría del verbo dokein, brillar, es decir, hablar sobre las apariencias que vienen hacia nosotros, como las olas al sol dirá el filósofo griego (Jacerme, 2010, 80)- y en las palabras poéticas y seductoras hay algo de diferente del "yo creo o siento esto", en el cual cabe cada posibilidad de comunicación y confrontación. A través de ellas puede empezar el viaje de la formación, de la educación a la pluralidad y complejidad, un "devenir subjetivo, devenir un ser existente conscientemente» (Arendt, 1968, 56), y también descubrir el sentido de la proximidad de los términos latinos educere y seducere (Recalcati, 2016).

Tal vez, entonces, no sea inútil volver a ese campo de batalla, para verificar si realmente el pensamiento que utiliza la persuasión retórica y el cortejo, las palabras hermosas y seductoras, es un capricho intrigante y juguetón del bomme de lettres, o si por el contrario es, como creemos poder mostrar aquí, una parte insustituible e inestimable de nuestra comprensión y de nuestro estar en el mundo. Un estar en el mundo que trata de quebrar la dominación totalitaria del Yo sobre el Otro. En este sentido, Emmanuel Lévinas, en su obra Totalidad e Infinito. Ensayo sobre la exterioridad, nos muestra los contornos de una razón que no conceptualiza, no domina y no posee, sino que recibe, que desea, o mejor, que aspira a "lo Infinito que lo deseable suscita» (Lévinas, 2002, 74). Esta razón, guiada por el eros, se abre a una relación educativa fecunda cuando ama el otro en su ser inescrutable, cuando respeta su misterio y su irreducible unicidad.

Si lográsemos en este breve ensayo mostrar la importancia de este pensamiento que aquí llamamos "poético", y si consiguiéramos hacer un retrato de sus potencialidades, sería entonces inevitable, como educadores, preguntarnos cuál es el mejor método, el mejor camino, para desarrollarlo de cara a las nuevas generaciones. Imaginamos que Hannah Arendt, que fue una atenta lectora y una comprometida crítica literaria, habría respondido que precisamente la literatura es un buen dispositivo formativo para lograr dicho objetivo. Pero, ya que no toda la literatura es útil para tal fin, es necesario -transformándonos nosotros mismos, educadores, antes que los alumnos, en lectores curiosos y apasionados- saber decidir qué obras escoger (lo cual entraña ya toda una educación poética y literaria) y adaptarlas a las edades y a las inclinaciones de los estudiantes. Es misión de otro tipo de investigación ofrecer precisas indicaciones prácticas y metodológicas en tal sentido; no obstante, en el último apartado, a modo de conclusión, usaremos a Hannah Arendt como una guía y una maestra, ya que en su original y aguda lectura de Franz Kafka 
encontramos un buen modelo de análisis interpretativo a seguir que sugiere, como posible elección, una extraordinaria y potente novela, El castillo, dentro del infinito patrimonio literario disponible.

\section{PENSAMIENTO POÉTICO O DE LA PRESENCIA}

La condición que nos permite ver un núcleo de verdad en los discursos desanclados de los conceptos de objetividad y utilidad -tan caros al vocabulario del pensamiento científico y abstracto- es la pluralidad. Como Arendt matiza, "la doxa no es ni ilusión subjetiva ni distorsión arbitraria» (Arendt, 2008, 57), sino el lugar donde poder encontrar la propia verdad, es decir, solo en el diálogo continuo consigo y con los demás, llevado adelante por Sócrates hasta la extrema consecuencia de la muerte, lo verdadero se levanta y, como nos indica la antigua palabra griega, aletheia, se libera de los velos que lo ocultan.

Pues, en este sentido, la opinión de la que habla no es la habladuría heideggeriana, un ruido del «ser» impersonal que distrae y confunde, sino un lenguaje desde el cual puede nacer un pensamiento poético; eso es lo que había hablado a propósito del amigo Walter Benjamin, un pensamiento crudo, nacido de un lenguaje cotidiano, de "los proverbios y modismos" (Arendt, 1990, 154), que toca la vida de una manera única e irrepetible ${ }^{1}$.

Sin embargo -si bien sea solo en la dialéctica, en un diálogo sin conclusión, que puede "[revelarse] la veracidad propia de la doxa» (Arendt, 2008, 53)- ese tipo de pensamiento asume la tarea onerosa de dar un significado a lo que deja sin palabras, en el estado de atónita maravilla del que la filosofía se origina y del que la ciencia huye; es decir, tiene que aceptar el peligro de subvertir las verdades compartidas y el sentido común sin tener nada que pueda reemplazarlos, excepto el silencio y la mudez del que partió.

Aun así, el quedarse desarmado e impotente puede decir algo de útil sobre la educación como construcción de sí mismo y como «un encuentro (y una transmisión) entre generaciones en la filiación del tiempo» (Bárcena, 2012, 53). Puede hacernos volver a la condición de asombro, de misterio y de conmoción desde donde empieza cada enseñanza y cada verdadero comprender. De hecho, de las obras arendtianas aflora una heurística de la impotencia y de la ineficiencia, que parece asumir el papel del centinela contra una pedagogía únicamente interesada en las competencias útiles por el mercado, en la clasificación estadística de los comportamientos. Un saber que ha quebrado su vínculo con la tradición

1. Las palabras de Walter Benjamin a este respecto son ejemplares y aclaran el valor del vínculo que conecta la narración con la vida y la experiencia: «Se puede [...] preguntar si la relación que tiene el narrador con su material, la vida humana, no es acaso una relación artesanal». La respuesta es por supuesto positiva porque, sigue el autor, el narrador elabora la experiencia de la vida «de forma sólida, útil y única» (Benjamin, 2008, 95). 
humanística y con aquella libertad de comienzo y búsqueda de cada recién nacido, donde reside el sentido de la educación.

En efecto, según Arendt, existen dos formas de pensamiento con las que el hombre se relaciona con el saber. En términos kantianos, Arendt está mirando a la diferencia entre el Intelecto y la Razón, la Verdad y el Significado. El intelecto, Verstand, no puede sino callarse y retirarse, dejando paso al pensamiento puro, a la razón, frente a las cuestiones últimas que el hombre no puede conocer y «en las que, sin embargo, no puede dejar de pensar» (Arendt, 1984, 25), lo que Wittgenstein había definido problemas no rozados y vitales (Wittgenstein, 1973, prop. 6.52). Pues la filósofa alemana cree firmemente en la necesidad humana de pensar más allá de los límites del conocimiento empírico, de lo que aparece como objetivo y cierto, y también de lo que puede ser utilizado por los hombres, lo útil y lo controlable.

Lo que está dibujando Hannah Arendt son los rasgos del pensamiento poético, pero además una facultad fuertemente puesta en peligro, que está olvidando las profundidades ricas y valiosas de su pasado y de su afectividad. Ya Horkheimer y Adorno, en la obra Dialéctica de la ilustración, habían subrayado, con acento claramente polémico, los pasos que la razón había dado hasta su reconocerse y aplastarse en la idea de razón instrumental, de pura racionalidad. Esta razón, que ya no persigue los fines sino únicamente lo que es funcional, útil y que puede dominar, es una razón que ha desaprendido a aspirar a lo que no conoce, a lo que no es pensable y que aparece como caos. La dramática conclusión a la que llegan los filósofos alemanes es que no solo no «debe existir ningún misterio, como tampoco el deseo de su revelación» (Horkheimer-Adorno, 2004, 61), atestiguando lo que Arendt define el descrédito total «en el que ha caído todo lo que no es visible, tangible, palpable» (Arendt, 1984, 23); un descrédito, a decir verdad, que ensombrece la importancia del conocimiento humanístico y del arte de lo que, si bien a menudo puede aparecer como lo inútil a la mirada del mercado, se torna, por su gratuidad y su desinterés, en lo verdaderamente útil, es decir, en lo que "nos ayuda a hacernos mejores» (Ordine, 2013, 9). De hecho, con gran empeño Martha Nussbaum denuncia el peligro por la formación de una ciudadanía democrática de la desaparición gradual en el sistema educativo de las artes y de las humanidades, de los saberes capaces de desarrollar la imaginación, la creatividad y el pensamiento crítico (Nussbaum, 2005, 2010).

Para tratar de volver a una dimensión profundamente humana, siguiendo un camino que Arendt parece indicar, se puede decir que es la poesía la que tiene el poder de conectarnos, de modo personal y auténtico, con las verdades más escurridizas. Es Marie Luise Knott, amiga y estudiante de la filósofa alemana, la que expresa válidamente la relación que enlaza, para Arendt, poesía y pensamiento:

La poesía desestabiliza el pensamiento por la fractura del lenguaje, introduciendo de contrabando sonido, ritmo e imagen, mediante la irrupción de lo estético. La escritura poética puede emanciparse en mayor medida del nivel de significación de las palabras y contribuir a que se abra un sentido, que luego puede desarrollarse 
"accesoriamente» de nuevo y de otro modo en cada lectura. En la poesía el lenguaje extrae de sí algo, bebe de lo desconocido, para llegar a las cercanías de una verdad distinta de la dada en el visible mundo exterior; es como paso a paso pudiera convertirse en una escalera hacia el vacío, según la fórmula que el poeta Franz Josef Czernin usó una vez (Knott, 2016, 107).

Pues la razón, cuando ha destruido la ilusión de que todo lo que acontece puede ser reducido a lo pensable, aunque, por el contrario, trabaja para «reforzar este impensable» (Arendt, 1968, 66), modifica su habitual percepción del mundo ${ }^{2}$ y se convierte en una razón poética que impulsa hacia una reflexión más intensa y compleja. Complejidad en el sentido literal de la palabra latina de abrazar (complector) los infinitos matices del ser humano, algo en que pueden relumbrar sentido, más que verdad, que es prerrogativa del intelecto puro.

La cuestión que interesa destacar en este contexto es que este tipo de comprensión consigue algo esencial: el poder de ligar todo lo que es inmaterial, sin corporeidad, con el arraigo en la materia de la vida, con la presencia, en un tiempo y en un espacio, de un sujeto vivo y de su manera personal de estar en el mundo.

Cuando reflexionamos, no siempre estamos buscando una solución o un concepto que clasifica y designa un acontecimiento, al desmaterializarlo. Lo que empuja a prestar atención, a tomar conciencia no es el deseo de abstracción y alienación, emblemáticamente expresado por la risa de la campesina tracia que se asombra frente a la distancia absoluta de Tales del mundo de la vida (Arendt, 1984, 102), sino el hacerse presencia, el tomar posición en la apariencia que nos involucra y nos maravilla. Ya que «no hay nada más sorprendente en este mundo nuestro que la casi infinita diversidad de sus apariencias, el enorme potencial de entretenimiento que poseen sus vistas, sus sonidos, y sus olores» (Arendt, 1984, 32).

Lo que la filosofía (y la pedagogía) parecen haber olvidado es la imposibilidad de distanciarse totalmente de la diversidad y de la materialidad de su casa terrenal, como nos muestra la interpretación arendtiana del mito platónico de la caverna. La violencia y las pérdidas que sufre el hombre de la caverna para alcanzar un mundo lógicamente perfecto, libre de sombras, lo privan de su casa y del vínculo de comprensión de sus compañeros de viaje y, también, de su razón poética.

Esto es porque Platón -por su operación rotatoria de la religión homérica y por aquella que María Zambrano llama su "condenación de la poesía" (Zambrano, 1996, 14) - quiso revertir la imagen de Hades recogida por el mundo homérico. Si, en la Odisea, el mundo oscuro es aquello subterráneo, sin corporeidad, con Platón

2. Bellamente Emmanuel Lévinas, en su obra De otro modo que ser. O más allá de la esencia, indica la fuerza de las obras de arte para romper nuestras formas habituales de pensamiento y modificar nuestra experiencia ordinaria del mundo. Escribe: «En el aislamiento todo obra de arte es, de este modo exótica, sin mundo, una esencia en diseminación. Desconocer lo Dicho propiamente dicho (cualquiera que sea su relatividad) en las proposiciones predicativas que toda obra de arte (plástica, sonora o poética) despierta y hace resonar a modo de exégesis es dar prueba de una sordera tan profunda como aquella que consiste en no entender dentro de lenguaje otra cosa que nombres» (LÉVINAS, 2003, 92). 
es «como si el mundo subterráneo del Hades hubiera emergido a la superficie de la tierra" (Arendt, 1996a, 43): con él, el Hades es el mundo que está a la luz, un mundo hecho de cuerpos, hombres en carne y huesos, atados al tiempo y al espacio de la caverna, o sea de nuestra casa terrenal. Lo que Platón había olvidado, según Arendt, es que solo en "el reino de las cosas perecederas y de los hombres mortales" (Arendt, 1996a, 42) la verdad puede mostrarse, cuando, frente al espectáculo del mundo, estamos buscando una forma particular de unidad y significación y nos volvemos espectadores. Pues ser espectadores entraña hallar un patrón narrativo y un destino a palabras y acciones de otro modo eliminados por el tiempo. El espectador no mira a la vida como si fuera un azar, va más allá de la pura casualidad: "Concebirla como un relato [...] [como si existiese] realmente [una] "melodía" de la vida a la cual se refería Blixen» (Sánchez Madrid, 2016, 162).

De hecho, quizá sea en el ensayo sobre Isak Dinesen, seudónimo elegido por la baronesa Karen Blixen, donde Arendt traza el poder de la narración para transformar los hechos contingentes en algo significativo y coherente, que deja entera, en los términos sartrianos, la propia responsabilidad del desciframiento (Sartre, 2007, 51). Algo que no acaba por dibujar un sistema cerrado y absoluto donde el hombre es movido por la necesidad y por un esquema preconcebido, lo que, por ejemplo, es el resultado de la idea de historia de Hegel. No estamos ante una razón legisladora sino una interpretativa y poética y por esto «el hecho de relatar una historia revela significado sin cometer el error de definirlo» (Arendt, 1990, 91).

Es siempre la imaginación la que empieza estos momentos de reflexión -que son, en términos heideggerianos, un pensar fuera del orden, un re-pensar afuera del flujo de los acontecimientos y del ruido del encuentro con el mundo (Arendt, 1984, 97)- y que, a diferencia del puro razonamiento lógico o especulativo, surge por el deseo de encontrar la realidad. De hecho, como había dicho Blixen, "sin repetir la vida en la imaginación no se puede estar del todo vivo, la "falta de imaginación" impide que las personas "existan”" (Arendt, 1990, 83), o sea, que encuentran su propio sentido y su propia capacidad de estar con los demás.

La misma Arendt examina el valor de la imaginación en la esfera política a través del mito bíblico de Salomón. El rey de Israel, pidiendo a Dios «el don de un corazón comprensivo» demuestra saber que "no la mera reflexión o los meros sentimientos" son los medios de los que el hombre puede utilizar para actuar en una comunidad, como hombre entre otros hombres, sino que es por la facultad de la imaginación, "la única brújula interna que tenemos», que nos podemos ver relámpagos de verdad. De hecho, explica la filósofa, solo «la imaginación nos permite ver las cosas en su adecuada perspectiva, nos permite ser lo bastante fuertes para poner a cierta distancia lo que nos resulta demasiado próximo [...]; y ser lo bastante generosos para salvar los abismos que nos separan de todo lo que resulta demasiado ajeno" (Arendt, 2002, 29-30).

En este sentido, el intento de abordar la cuestión del pensamiento poético desde el ámbito de la educación, sentido de manera acuciante por algunos pedagogos contemporáneos, revela la proximidad de la razón poética con una idea de la 
presencia, con una disposición a prestar atención, que se desarrolla en una filosofía de la educación como una forma de vida. En este punto, Fernando Bárcena escribe:

Deseo plantear la pregunta por la filosofía de la educación como algo que tiene que ver, no ya con la esencia o con la significación, sino con la relación entre experiencia y sentido. Y esta relación supone un interrogante poético (ni ontológico ni hermenéutico): ¿Cómo me hago presente en lo que hago y en lo que pienso? El propósito de un filosofar educativo no sería ya la pretensión de cambiar lo que hay, sino aprender a mirar lo que ya vemos, pero no nos damos cuenta: prestar atención a lo que hay haciéndonos presentes en la realidad (Bárcena, 2012, 33).

Aprender a mirar, adquirir un sentido comprensible de los acontecimientos que ocurran, aquí significa también enamorarse del propio destino, tener fides, confianza, en la propia vida, al vivirla como algo que se ha elegido y que, al final, nos permite reconciliarnos con la realidad, aun cuando es dolorosa ${ }^{3}$. A este respecto, Arendt escribe: "Para ello, para ser uno con el propio destino, de modo que nadie pueda distinguir a la bailarina del baile, la respuesta a la pregunta: «QQuién eres? será [...]: "Permítame... responderle en la forma clásica y contarle una historia"” (Arendt, 1990, 90).

\section{LA POESÍA ES MAESTRA}

A través de una lectura pedagógica de Hannah Arendt, se podría dar por sentada la importancia que tiene la educación a la hora de reflexionar sobre la razón poética como posibilidad humana de encontrar sentido y darse una forma, Bildung, y sobre el desarrollo de la imaginación, la que, dicho según la famosa formulación kantiana, es junto al intelecto una de las facultades más importantes del conocer humano.

Sin embargo, todavía, existe otra cuestión estrechamente ligada a la idea de pensamiento poético, es decir, la tradición y el patrimonio cultural y artístico que son el caldo de cultivo sobre el que puede brotar una manera nueva de ver el mundo y de formarse: un saber humanístico, a menudo, desaparecido, minusvalorado, detrás del mito de las competencias y de la competición del mundo laboral.

3. En este sentido, me parece bien recordar la narración filosófica de Hannah Arendt sobre Rahel Varnhagen, Rabel Varnhagen: the Life of a Jewess (1958), en la que el origen judío tan odiado y rechazado en la juventud de Rahel se vuelve en aquel destino del nacimiento que ha dibujado los límites de su historia, algo irrenunciable y esencial. De hecho, como Arendt escribe, Rahel Varnhagen dijo antes de morir: "Con entusiasmo sublime pienso en los que fueron mis orígenes y en todo ese eslabonamiento del destino por el que los más viejos recuerdos del género humano enlazan con el estado de cosas más reciente [...]. Lo que en mi vida fue durante tanto tiempo la mayor vergüenza, la pena y la infelicidad más amargas -haber nacido judía- no quisiera ahora que me faltara por nada del mundo" (ARENDT, 2000, 21). 
La tradición, en este sentido muy cercana al concepto de autoridad, muchas veces comentada por Arendt, ofrece a la nueva generación una guía para el futuro, una estructura de acogida $a^{4}$, "que selecciona y denomina, que transmite y preserva, que indica dónde están los tesoros y cuál es su valor» (Arendt, 1996a, 11), ya que, sin pasado, sin una vida que compartir, permanece solo zoé, o sea el mundo cíclico y previsible de la especie humana. Ahora bien, es la cultura, que Arendt entiende en su sentido cercano al lema latino colere (cultivar, cuidar con amor, habitar), la que puede humanizar el mundo, hacerlo una casa que acoge a los recién llegados y su disposición a crear algo nuevo, nunca antes existido (biós).

Este nos fuerza a pensar sobre el hecho de que «la esencia de la educación es la natalidad" (Arendt, 1996a, 186) y, por tanto, tiene que ver con la introducción de los jóvenes en un mundo viejo para que este mundo no sea destruido por las instancias innovadoras de los recién nacidos, ni muera por su falta de renovación.

A este respecto, hablando de la desmemoria, Arendt escribe que

aparte de los propios contenidos que pueden perderse, significaría que, hablando en términos humanos, nos privaríamos de una dimensión: la de la profundidad en la existencia humana, porque la memoria y la profundidad son lo mismo, o mejor aún, el hombre no puede lograr la profundidad si no es a través del recuerdo (Arendt, 1996a, 104).

A partir de la importancia de la memoria, los educadores tienen la responsabilidad de reforzar el vínculo que une a los nuevos con la historia y la tradición que estaba antes de su llegada, o bien de la perpetuación del mundo. Existe la necesidad de trabajar por el conservadurismo, en el sentido de mantener vivo aquel mundo en común, hecho de palabras, actos y obras, que es la casa segura donde poder aprender a comunicar con los otros y descubrirse a sí mismo. En este sentido Arendt escribió: "Ante el niño, el maestro es una especie de representante de todos los adultos, que le muestra los detalles y le dice: "éste es nuestro mundo"» (Arendt, 1996a, 201).

Por lo tanto, para no caer en el distanciamiento del mundo, tan radical en la sociedad moderna de masas, los educadores tienen que mostrar «un respeto extraordinario hacia el pasado" (Arendt, 1996a, 205) y trabajar para transmitir el espíritu del mundo. El cual, a menudo, está formado de verdades e ideas que no es posible ver ni tocar, una mezcla de pensamientos y acontecimientos huidizos y que

4. De hecho, según Lluís Duch, la cultura, la lengua materna, la religión, las tradiciones constituyen caminos esenciales que llevan los recién nacidos desde el caos, un mundo donde solo los instintos hacen de guía, a «un cosmos informado, en el cual la orientación para proceder a la búsqueda del sentido podía ser posible» (Duch, 1998, 24). En este sentido, escribe Duch que la "Socialización, la identificación, el empalabramiento, la anticipación simbólica sólo llegan a convertirse en algo verdaderamente importante en el tejido de la existencia humana por mediación de las estructuras de acogida, que son aquellos elementos relacionales que, en y desde el presente, permiten establecer una vinculación creativa con el pasado, a fin de imaginar y configurar el futuro» (Duch, 1998, 27). 
no pueden ser contados y traspasados con el lenguaje científico, pero que, a pesar de este, constituyen todo lo que es vital y esencial para fundar un nuevo mundo.

Quiero decir que hay preguntas y búsquedas esenciales que empujan a los hombres a romper los límites del saber intelectual, por ejemplo, aquellas sobre la inmortalidad del alma, la libertad del hombre, el sentido del sufrimiento, asuntos que «solo pueden ser comprendidos como "verdades subjetivas"; [y que] no pueden ser conocidas como verdades objetivas» (Arendt, 1968, 56); verdades que necesitan de una comunicación entre los hombres diferente y que supera los límites del tiempo cronológico y que se vuelve en un diálogo sin fin con el pasado y la tradición.

Pero, como bien dice Michel Foucault en la obra El orden del discurso, empezar una conversación lleva consigo el miedo a lo que puede haber de temible en cada palabra. Pues hablar (incluso con los grandes pensadores del pasado o entre profesor y estudiante) es siempre una toma de posición, un asumir la responsabilidad de elegir lo que hay que decir y lo que hay que callar. El deseo de dejarse "arrastrar [...] como algo abandonado, flotante, dichoso" (Foucault, 1992, 10) al silencio se quiebra por la fuerza del choque entre la materialidad del discurso y la libertad absoluta de lo no está dicho todavía. Sin embargo, para Foucault hay otro peligro al que enfrentarse: todos los procedimientos aplicados para controlar y limitar justo aquella espontaneidad de las palabras que reside en cada comienzo del discurso.

Todo esto significa crear, más o menos violentamente, un conjunto de verdades de forma insidiosamente universal, donde el pensamiento crítico es reemplazado por la uniformidad y por la imposibilidad de un formarse autónomo. Por eso Foucault escribe: "¿Qué es, después de todo, un sistema de enseñanza, sino una ritualización del habla; sino una cualificación y una fijación de las funciones para los sujetos que hablan; sino la constitución de un grupo doctrinal cuando menos difuso; sino una distribución y una adecuación del discurso con sus poderes y saberes?» (Foucault, 1992, 38).

Entonces, quizá sea justo en las palabras, entendidas como aparición narrativa y poética, o en las creaciones artísticas, donde se puede ver una posibilidad de contrarrestar la coacción de la verdad oficial y de realizar una verdadera comprensión entre los hombres. El papel del artista y del pensador, gracias a un libro, a una música o a una película, confiere a la experiencia humana su indispensable objetividad, su estancia en el tiempo, al inmortalizarla, athanatizein, aun cuando esta experiencia no halla palabras ni una lógica rigurosa5.

5. A este respecto, Arendt escribe: «Cualquier cosa que hagan los hombres para darse un cobijo y poner un techo sobre sus cabezas [...] puede servir como un hogar [...]; pero esto no implica que esos actos den origen al mundo, y mucho menos a la cultura. En el sentido propio de la palabra, ese hogar mundano se convierte en un mundo solo cuando la totalidad de las cosas fabricadas se organiza de modo que pueda resistir el proceso consumidor de la vida de las personas que habitan en él y, de esa manera, sobrevivirlas. Hablamos de cultura en el caso exclusivo de que esa supervivencia esté 
De hecho, es en la narración y en cada transposición artística donde la vida íntima se transforma, desindividualizándose, y mostrándose al mundo «[adquiere] una especie de realidad que, fuera cual fuese su intensidad, no podían haber tenido antes». Más bien, aclara Arendt inmediatamente después, «la presencia de otros que ven lo que vemos y oyen lo que ó́mos nos asegura de la realidad del mundo» (Arendt, 1996b, 60).

Paul Ricoeur, comentando los conocidos conceptos arendtianos de labor, trabajo y acción, nos muestra la diferencia entre el tiempo como passage, que se refiere al reino de las cosas que se gastan (labor), y el tiempo como duration, de los documentos y de los monumentos del pasado. Concluye que solo la memoria y la poesía garantizan la conservación de la grandeza humana y el convivir como una pluralidad. "Esto es posible -escribe Ricoeur- porque la ciudad es a kind of organized remembrance. Lo que el poeta hace es componer una mimēsis, es decir, una imitación creativa de la acción en su dimensión política» ([mi traducción] Ricoeur, 1983, 69).

Además, el mundo de las obras de arte y de la tradición es una casa duradera donde se pueden aprender las palabras nunca dichas, los recuerdos lejanos, la sensación de familiaridad que compartimos con las personas con las que habitamos. A través de las obras de arte buscamos en el mar profundo de la imaginación humana, de la historia del pensamiento, y somos como pescadores que pueden ver y agarrar la realidad del mundo y, al final, sacar a la luz los pedazos más hermosos, "el "coral" y las "perlas"”, los pensamientos y las tradiciones del hombre, que la "trasformación del mar" convirtió en "fragmentos del pasado" (Arendt, 1984, $242-243)^{6}$.

En este sentido, Arendt amaba las metáforas, porque son precisamente capaces de meta-pherein, o sea, de transportar lo invisible en lo visible, en apariencias, sonidos hermosos y profundos: la prueba de que no existe separación entre la experiencia de vivir, de existir y la experiencia de pensar, entre el cuerpo y la mente. Asimismo, las metáforas son, según Arendt, los hilos para ligar la mente con el mundo, aun cuando, por distracción, se haya perdido contacto con él. Ya que, como Arendt dice en su hermoso discurso por el premio Lessing (1959), "la carencia de mundo es siempre una forma de inhumanidad" (Arendt, 1990, 23).

La educación puede recurrir a las metáforas y a las obras de arte, que son la casa terrenal duradera de los hombres, para coser los recorridos individuales de los jóvenes en formación con el mundo, porque, como decía Arendt, es en el arte

asegurada; y cuando nos enfrentamos con cosas que existen independientemente de todas las referencias utilitarias [...] hablamos de obras de arte» (Arendt, 2003, 321).

6. En su hermoso ensayo dedicado a Walter Benjamin, Arendt escribe: «Este pensar [poético], alimentado por el presente, trabaja con los "fragmentos de pensamiento" que puede arrancar del pasado y reunir en torno suyo. Como el buscador de perlas que baja al fondo del mar no para excavarlo y exponerlo al lux sino para extraer lo valioso y extraño, las perlas y coral, de las profundidades y llevarlos a la superficie [...] al mundo de los vivos -como "fragmentos de pensamiento" como algo "rico y extraño”- y quizás, incluso, como Urphänomene eternos» (ARENDT, 1971, 70-71). 
donde se puede ver la estabilidad del mundo, y es en esta estabilidad donde los jóvenes pueden aprender poco a poco a conocerse, a encontrarse y a manifestarse ${ }^{7}$.

Volcando el célebre aforismo de René Char, muchas veces citado por Arendt, Notre héritage n'est précedé d'aucun testament (Nuestra herencia no proviene de ningún testamento), nuestra tradición, cuando seguimos dándole crédito y valor, transmitiéndola a la nueva generación, puede revelarse el testamento para nuestra herencia, una guía para vivir en el mundo que nos ha sido entregado. Y es por esa razón que los educadores tendrían que reforzar su vínculo de responsabilidad con el pasado y la memoria, mirando el futuro. Como bien escribe Fernando Bárcena, "el educador [...] no debe aspirar a crear un mundo nuevo con seres nuevos. Ésta es una tentación totalitaria. Más bien, representa un mundo más antiguo, en cierto modo inmemorial, un mundo que es tiempo y que se transmite creativamente para que la pregunta por el sentido no quede cancelada» (Bárcena, 2006, 225).

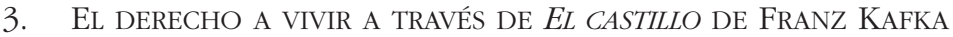

Leyendo las páginas de Hannah Arendt se puede imaginar que el hombre sea un ciudadano que ocupa un lugar particular, un mundo-teatro formado por relaciones y acciones, actores y espectadores, objetos perecederos, como las obras de arte, y gestos y palabras que desaparecen detrás de la cortina: aquí es donde se crea algo nuevo, o sea aparece, se manifiesta con su propia presencia. Por este motivo Giorgio Agamben dice que en la tierra «el hombre tiene un estatus poético, porque es la poiesis la que funda para él el espacio original de su mundo [...]. Solo porque él es capaz del poder más inquietante, de la producción en la presencia, es capaz de práctica, de actividad libre y deseada” (Agamben, 2005, 163).

Sin embargo, esta capacidad de los hombres de poesis, de crear libremente su estancia sobre la tierra, a menudo, está amenazada por fuerzas contrarias, tal vez invisibles, y aun así poderosas, como Arendt nos cuenta a través de una obra de Franz Kafka, El castillo. Esta interpretación arendtiana no solo nos parece un ejemplo perfecto de lo que una narración puede enseñar, involucrándonos en una comunicación educativa y provechosa entre nosotros y el pasado; al mismo tiempo, la belleza del relato de Kafka arroja luz sobre el valor de la razón poética, o sea, sobre la importancia de actuar un tipo de pensamiento capaz de trastocamiento, de poner en duda todo lo que es necesario y eficiente.

El protagonista de El castillo, un agrimensor llamado sencillamente K., un hombre con ningún rasgo distintivo, llega como forastero a una ciudad que muestra, de inmediato, los rasgos inquietantes de un sistema de poder cerrado e ininteligible.

7. En este sentido, dirá Giorgio Agamben, las obras de arte tienen un ritmo propio, que «otorga a los hombres tanto la estancia estática en una dimensión original, como la caída en la fuga del tiempo mensurable [...]. Es el éxtasis original que le abre al hombre el espacio de su mundo, a partir del cual solo él puede vivir la experiencia de la libertad y de la alienación, de la conciencia histórica y del extravío en el tiempo, de la verdad y del error» (AGAMBEN, 2005, 162-163). 
Pero, como todos los héroes kafkianos, K. querría hacerse presencia, no adaptarse sino comprender "qué es propiamente lo que pasa con las cosas que se derriten a mi alrededor como la nieve mientras para los demás un vasito de aguardiente ya es firme como un monumento» (Arendt, 2005, 65).

El deseo de vivir, de ver respectados sus derechos, tener una casa, un trabajo, una familia, la ciudadanía, hace de $\mathrm{K}$. un caso paradigmático del inacabamiento y de la precariedad que el pueblo judío padeció. Pero, en este personaje, parecen aglutinarse todos los seres humanos -desde los refugiados políticos de las nuevas guerras o las parejas homosexuales, hasta los más o menos jóvenes en busca de trabajo- que quieren huir del aislamiento total de la sociedad de masas, buscar el sentido de su propia humanidad, o sea, lograr un segundo nacimiento, ser hombres plenamente realizados en la relación con los demás.

Se puede decir que la trama de este relato se desarrolla en tres etapas. En la primera, los habitantes del pueblo, encolerizados por la postura antiautoritaria de K., tratan de convencer al extraño de que sus deseos son absurdos, en contra de toda lógica y, al final, una pretensión demasiado grande. El propósito no declarado es desmaterializar a K.: si sus aspiraciones más fuertes y íntimas son solo fantasías, él mismo es una fantasía, un fantasma, más bien un nadie.

Este reducir la vida humana a algo superfluo, el no poder tomar en serio la propia existencia, que para Hannah Arendt fue la mayor perversión de los campos de concentración del régimen nazi, tiene que ser de nuevo pensada; de hecho, escribe en la obra Los orígenes del totalitarismo, el «intento totalitario de hacer superfluos a los hombres refleja la experiencia que las masas modernas tienen de su superficialidad en una Tierra superpoblada” (Arendt, 1998, 556). Ser superfluos significa la destrucción de la individualidad, desaparecer detrás de la lógica de una máquina del poder que utiliza el terror para controlar el incontrolable, o sea, aquella libertad de acción posible solo en el encuentro con los demás ${ }^{8}$.

De hecho, estar juntos, ser una pluralidad, no es nunca fusionarse, sino tener siempre abierto el espacio que separa y une a los hombres, es decir, la palabra. Contrariamente a lo que pasa con el conformismo, los hombres, cuando transforman el mundo en el espacio público, actúan más que se comportan, que es reproducir conductas previsibles, condicionadas y normalizadas.

Solo cuando hay comunicación auténtica, cuando el logos cae en su máxima profunda complejidad y se convierte en dialogos, cuando un pensamiento crítico encuentra otro pensamiento crítico, se puede hablar de espacio público. Por esto Hannah Arendt escribe: «El fin del mundo común ha llegado cuando se ve solo bajo

8. Arendt así, con claridad y sencillez, corrobora: «Porque destruir la individualidad es destruir la espontaneidad, el poder del hombre para comenzar algo nuevo a partir de sus propios recursos, algo que no puede ser explicado sobre la base de reacciones al medio ambiente y a los acontecimientos. Solo quedan entonces fantasmales marionetas de rostros humanos que se comportan todas como el perro de los experimentos de Pavlov, que reaccionan todas con perfecta seguridad incluso cuando se dirigen hacia su propia muerte y que no hacen más que reaccionar. Este es el verdadero triunfo del sistema” (ARENDT, 1998, 553) 
un aspecto y se le permite presentarse únicamente bajo una perspectiva» (Arendt, 1996b, 67). Y continúa, "la pluralidad humana es la paradójica pluralidad de los seres únicos. El discurso y la acción revelan esta única cualidad de ser distinto» (Arendt, 1996b, 200). Es esta incapacidad de K. de renunciar a su propia identidad (su trabajo, sus aspiraciones) y, al mismo tiempo, de renunciar a compartir su vida con los habitantes de la ciudad, que hace vivir a K. un dolor tan grande y paradójico: amar un mundo que lo rechaza.

En este sentido, Arendt a menudo reflexiona sobre el concepto de amor mundi, que es la fuga del absoluto aislamiento del individuo y, simultáneamente, es desear ser testigo del aparecer de los otros. Es tener cuidado con la pluralidad que nos permite ser vistos, oídos, tocados y sin la cual no hay existencia humana. "Así, el idioma de los romanos -escribe Arendt- [...] empleaba las expresiones "vivir" y "estar entre hombres" (inter homines esse) o "morir" y "cesar de estar entre hombres" (inter homines esse desinere) como sinónimos" (Arendt, 1996b, 22).

De hecho, Hannah Arendt estaba convencida de que la incapacidad de tener un mundo en común y de pensamiento crítico, debido a la incapacidad de comunicación, habría llevado al hombre a encerrarse en la vida privada -en la privacy como privación de la esfera pública- a volverse alguien capaz de hacer el peor de los males, o sea un mal banal, sin pensamiento, sin la posibilidad de comprender lo que está mal y qué está bien, como reconocen al final incluso los habitantes del pueblo de El castillo?.

En la segunda fase del relato K. tiene que elegir si ser un trabajador del castillo, alejarse de la comunidad con la que en vez desea convivir, o perder la protección del castillo y tratar de convertirse en parte del pueblo. K. decide asimilarse a los habitantes; de hecho, es allí, entre los lugareños, donde él quiere vivir y convertirse en alguien indistinguible. Por esta razón Arendt lo llama un hombre de buena voluntad, ya que «nunca exige más derecho que el que corresponde a todo ser humano y tiende a no conformarse nunca con menos» (Arendt, 2005, 69).

El meollo del problema aquí, que asombra a K. y a todos nosotros, sus lectores, es que la ciudad lo rechaza y lo teme, no entiende su amor mundi. Su error, su locura, incluso su crimen, están en no someterse al urdido de la necesidad impuesta por el castillo, esta mentira que obliga todos los habitantes a vivir todo lo que debería ser la normalidad como «destino, regalo o maldición: en cualquier caso como suceso impenetrable que puede contarse pero no entenderse, ya que en sí mismo nadie ha hecho nada” (Arendt, 2005, 71) . $^{10}$.

9. Arendt escribe respecto a esto que "Vivir juntos en el mundo significa en esencia que un mundo de cosas está entre quienes lo tienen en común, al igual que la mesa está entre los que se sientan alrededor; el mundo [...] une y separa a los hombres al mismo tiempo. La esfera pública, al igual que el mundo en común, nos junta y no obstante impide que caigamos uno sobre otro, por decirlo así» (ARENDT, 1996b, 62).

10. En este sentido, como afirma Nuria Sánchez Madrid, si nadie puede ya decir lo que es justo o injusto, si cada libertad de elegir es destrozada, "la condición humana capitula su dimensión activa y adopta creencias de carácter demonológico que escinden el orden del lógos. Lo que ocurre, en efecto, 
La renuncia a su propia dignidad, la sensación que para alcanzar una forma de serenidad hay que aceptar sin protestar las reglas del juego -tan difusa en la sociedad de la precariedad- llega K. a dejar el trabajo de agrimensor (un trabajo antiguo, atado a la tierra y, tal vez, ya no útil) y a aceptar el trabajo de bedel bajo la presión tiránica del profesor del pueblo, uniéndose a las miserias de los lugareños.

Pero, de ellos, no puede compartir el terror por el castillo, por la necesidad. Él acaba siendo, a pesar de todo, un fabricator mundi, un hombre de buena voluntad que no renuncia a su propio poder ${ }^{11}$. En el esfuerzo de enfrentar el sistema oscuro que exige de ordenar la trama de su vida, muere de agotamiento, ya que, escribe Arendt, "lo que él había querido sobrepasa las fuerzas de un hombre solo» (Arendt, 2005, 72).

En la tercera y última etapa del relato Kafka cuenta como K., después de su muerte, se convierte para el pueblo en un modelo a seguir, en alguien que, aunque frágil y vulnerable, quiere, o mejor dicho exige, ser existencia humana sobre la tierra, no por misericordia o limosnas, residuo andante de decisiones de los demás. Él sobrevive en la memoria de los lugareños porque no ha renunciado ni a ser un miembro de la comunidad ni a su pretensión de cambiar las cosas que pasan y de construir algo de nuevo, según el principio arendtiano de natalidad. De hecho, así Hannah Arendt termina su ensayo sobre Franz Kafka, con un párrafo que vale la pena citar entero, a pesar de su extensión:

Para asegurarse al menos la posibilidad de llegar a ser un ciudadano más de un mundo liberado del fantasma de la sangre y del hechizo del horror [...] no pudo menos de anticipar la destrucción del mundo existente. Sus novelas son una anticipación de esta destrucción, con cuyas ruinas construye la imagen sublime del hombre como un modelo de la buena voluntad, que puede mover montañas y edificar nuevos mundos [...] porque a este hombre los dioses, por el solo hecho de tener buena voluntad, le han dado un corazón indestructible. Y como los personajes de Kafka no son personas reales con las que podamos identificarnos, como sólo son modelos y, pese a tener un nombre, permanecen en el anonimato, todos podemos sentirnos aludidos y hasta llamados personalmente. Pues ese hombre de buena voluntad podemos serlo todos y cada uno de nosotros, quizás hasta tú y yo (Arendt, 2005, 106-107).

deja de ser comprensible, pero no por ello deja de acontecer, influyendo con fuerza en el ser humano" (SÁNCHEZ MADRID, 2016, 79).

11. Son, en verdad, muy bellas las palabras con la que Arendt, en la obra La condición humana, describe el verdadero sentido del poder: «El poder solo es realidad donde palabra y acto no se han separado, donde las palabras no están vacías y los hechos no son brutales, donde las palabras no se emplean para velar intenciones sino para descubrir realidades, y los actos no se usan para violar y destruir sino para establecer relaciones y crear nuevas realidades». Y termina, "quienquiera que, por las razones que sea, se aísla y no participa en ese estar unido, sufre la pérdida de poder y queda impotente, por muy grande que sea su fuerza y muy válidas sus razones» (ARENDT, 1996b, 223-224). 


\section{REFERENCIAS BIBLIOGRÁFICAS}

Agamben, G. (2005) El hombre sin contenido. Barcelona, Áltera.

ARENDT, H. (1968) La filosofía de la existencia. Tarea, 1, 48-68.

ARENDT, H. (1971) Walter Benjamin; Bertolt Brecht; Hermann Broch; Rosa Luxemburgo. Barcelona, Editorial Anagramma.

ARENDT, H. (1984) La vida del espíritu. El pensar, la voluntad y el juicio en la filosofía y en la política. Madrid, Centro de Estudios Constitucionales.

ARENDT, H. (1990) Hombres en tiempos de oscuridad. Barcelona, Gedisa.

ARENDT, H. (1996a) Entre el pasado y el futuro. Ocho ejercicios sobre la reflexión política. Barcelona, Península.

ARENDT, H. (1996b) La condición bumana. Barcelona, Paidós.

ARENDT, H. (1998) Los orígenes del totalitarismo. Madrid, Taurus.

ARENDT, H. (2000) Rahel Varnhagen. Vida de una mujer judia. Barcelona, Lumen.

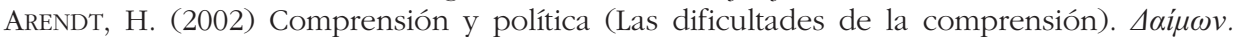
Revista de Filosofía, 26, 17-30.

ARENDT, H. (2005) La tradición oculta. Buenos Aires, Paidós.

ARENDT, H. (2008) La promesa de la política. Barcelona, Paidós.

BÁrCENA, F. (2012) Una pedagogía de la presencia. Crítica filosófica de la impostura pedagógica. Teoría de la Educación. Revista Interuniversitaria, 24: 2, 25-57.

Bárcena, F. (2006) Hannah Arendt. Una filosofía de la natalidad. Barcelona, Herder.

Benjamin, W. (2008) El narrador. Santiago de Chile, Metales Pesados.

Duch, L. (1998), La educación y la crisis de la modernidad. Barcelona, Paidós.

Foucault, M. (1992) El orden del discurso. Buenos Aires, Tusquets Editores.

Horkheimer, M. y Adorno, T. W. (2004) Dialéctica de la ilustración. Fragmentos filosóficos. Madrid, Trotta.

Jacerme, P. (2010) Introduzione alla filosofia occidentale. Eraclito, Parmenide, Platone, Cartesio. Milano, Christian Marinotti Edizioni.

KnotT, M. L. (2016) Desaprender. Caminos del pensamiento de Hannah Arendt. Barcelona, Herder.

LÉVINAS, E. (2002) Totalidad e infinito. Ensayo sobre la exterioridad. Salamanca, Sigueme.

LÉvinas, E. (2003) De otro modo que ser. O más allá de la esencia. Salamanca, Sigueme.

Nussbaum, M. C. (2005) El cultivo de la bumanidad. Una defensa clásica de la reforma en la educación liberal. Barcelona, Paidós.

Nussbaum, M. C. (2010) Sin fines de lucro. Por qué la democracia necesita de las bumanidades. Madrid, Katz.

Ordine, N. (2013) La utilidad de lo inútil. Manifiesto. Barcelona, Acantilado.

Recalcati, M. (2016) La hora de clase. Por una erótica de la enseñanza. Barcelona, Anagrama.

Ricoeur, P. (1983) Action, Story and History: On Re-reading. The Human Condition, Salmagundi, 60, 61-72.

SÁNCHEZ MAdrid, N. (ed.) (2016) Hannah Arendt y la literatura. Barcelona, Bellaterra.

SARTRE, J. P. (2007) El existencialismo es un bumanismo. Barcelona, Edhasa.

Wittgenstein, L. (1973) Tractatus logico-philosophicus. Madrid, Alianza.

Zambrano, M. (1996) Filosofía y poesía. México, FCE. 